\title{
TOXICITY OF AUTO-DETOXIFIED Jatropha curcas Linnaeus, 1753 KERNEL CAKE MIXTURES WITH BOVINE BLOOD (ADMJKC/BB) USING BRINE SHRIMP Artemia salina Linnaeus, 1758
}

\author{
Divine EWANE ${ }^{1 \otimes \otimes}$, Benedicta O. OBEN ${ }^{2}$, Kenneth Jacob Ngoh NDAMUKONG ${ }^{1}$, Kingsley A. ETCHU3 ${ }^{3}$ Eugene \\ E. EHABE ${ }^{3}$, Jane M. $\mathrm{CHAH}^{4}$, Kennedy F. $\mathrm{CHAH}^{5}$ and Pius MBU OBEN2
}

${ }^{1}$ Department of Animal Science, Faculty of Agriculture and Veterinary Medicine, University of Buea, P0 Box 63, Buea, Cameroon ${ }^{2}$ Department of Fisheries and Aquatic Resources Management, Faculty of Agriculture and Veterinary Medicine, University of Buea, PO Box 63, Buea, Cameroon

${ }^{3}$ Directorate of Scientific Research, Institute of Agricultural Research for Development, P.O. Box 2123, Yaounde, Cameroon

${ }^{4}$ Department of Agricultural Extension, Faculty of Agriculture, University of Nigeria, Nsukka, Enugu State, Nigeria

${ }^{5}$ Department of Veterinary Pathology and Microbiology, Faculty of Veterinary Medicine, University of Nigeria, Nsukka, Enugu State, Nigeria

Email: ewane.divine@ubuea.cm ; (D) ORCID: 0000-0002-7807-4056

Supporting Information

\begin{abstract}
In present study, brine shrimp (Artemia salina L.) was used to determine the toxicity of autodetoxified Jatropha kernel cake (JKC) mixed with bovine blood (ADMJKC/bb). The powdered-JKC was mixed with bovine blood $(\mathrm{bb})$ at three ratios $(1: 1=X, 2: 1=Y$ and 3:1=Z of JKC: $b b)$ and the resultant mixtures processed using four protocols: Heated, Spread Dry $=1$, Unheated Spread Dry $=2$, Heated Spread Remoisten to $66 \%$ dry matter $(D M)=3$ and Unheated Spread Remoistened to $66 \% \mathrm{DM}=4$ ). The resultant 12 treatment combinations (X1, X2, X3, X4, Y1, Y2, Y3, Y4, Z1, Z2, Z3 and Z4) were placed in a Solar J. curcas auto-detoxification apparatus from where samples were retrieved periodically and evaluated for detoxification using the brine shrimp lethality test. There were no significant differences within the same ratio of mixes among the four protocols. However, there was a tendency for mean $\mathrm{LC}_{50}$ values to increase between the ratios. Specifically, Protocol 2 recorded a significant difference between X2 and Z2 treatments, having 1:1 and 3:1 JKC: bb mixes respectively. Upon ranking the level of auto-detoxification, the most detoxified treatments $\left(Z 2\right.$ with $L_{50}=4674$ and $Z 4$ with $L C_{50}=3692$ ) differed significantly from the least two (X1 with $L C_{50}=1383$ and $X 2$ with $\left.L C_{50}=1459\right)$. Addition of bovine blood to JKC increased the dynamics of JKC auto-detoxification, probably due to the presence of some innate auto-detoxifying microbial inoculum and bovine blood which boost the rapid growth, development and succession of these microbes. Thus combining JKC with bovine blood is complementary for JKC auto-detoxification, with the most detoxified ingredients (Z2, Z4 and Y3) appearing most suitable for further development and testing as feed ingredient for farm animals.
\end{abstract}

Keywords: Auto-detoxification, Bovine blood, Feedstuff, Jatropha, Shrimp.

Abbreviations: ADJKC; auto-detoxified Jatropha kernel cake; ADMJKC/bb: auto-detoxified mixtures Jatropha kernel cake and bovine blood; ANOVA: analysis of variance; BSLT: Brine Shrimp Lethality Test; bb: bovine blood; CMJKC/bbE: crude methanol auto-detoxified mixtures of Jatropha kernel cake with bovine blood extracts; DJADA: Diffuse daylight Jatropha curcas auto-detoxification apparatus; DMSO: dimethyl sulfoxide; DMRT: Duncan's Multiple Range Test; FAO: Food and Agriculture Organization of the United Nations; IBM: International Business Machines; JKC: Jatropha kernel cake; LC 50 : Lethal concentration killing $50 \%$ of test organisms; NRC: National Research Council; SJADA: Solar Jatropha curcas auto-detoxification apparatus; SPSS: Statistical package for social sciences; UDC: un-moistened diffuse daylight spread; USS: un-moistened solar spread; X1: Jatropha kernel cake and bovine blood, mixed at a ratio of 1:1. Heated, spread dried without remoistening; X2: Jatropha kernel cake and bovine blood, mixed at a ratio of 1:1. Unheated, spread dried without remoistening; X3: Jatropha kernel cake and bovine blood, mixed at a ratio of 1:1. Heated, spread dried, remoisten to $66 \%$ dry matter; X4: Jatropha kernel cake and bovine blood, mixed at a ratio of 1:1. Unheated, spread dried, Remoistened to $66 \%$ dry matter; Y1: Jatropha kernel cake and bovine blood, mixed at a ratio of 2:1. Heated, spread dried without remoistening; Y2: Jatropha kernel cake and bovine blood, mixed at a ratio of 2:1. Unheated, spread dried without remoistening; Y3: Jatropha kernel cake and bovine blood, mixed at a ratio of 2:1. Heated, spread dried, remoisten to $66 \%$ dry matter; Y4: Jatropha kernel cake and bovine blood, mixed at a ratio of 2:1. Unheated, spread dried, remoistened to $66 \%$ dry matter; Z1: Jatropha kernel cake and bovine blood, mixed at a ratio of 3:1. Heated, spread dried without remoistening; Z2: Jatropha kernel cake and bovine blood, mixed at a ratio of 3:1. Unheated, spread dried without remoistening; Z3: Jatropha kernel cake and bovine blood, mixed at a ratio of 3:1. Heated, spread dried, remoisten to $66 \%$ dry matter; Z4: Jatropha kernel cake and bovine blood, mixed at a ratio of 3:1. Unheated, spread dried, Remoistened to $66 \%$ dry matter.

\section{INTRODUCTION}

Jatropha curcas has shown some promise as a crop from which biofuels can be produced without compromising human food needs (Nithiyanantham et al., 2012; Maghuly and Laimer, 2013). However, despite global excitement on its potentials, at current levels of technology, value-addition from its by-products and co-products is necessary in order for viability of the sector to be ensured (Makkar et al., 2012). One of the by-products being evaluated in this regard is Jatropha kernel cake (JKC), the remnants obtained after extraction of oil from Jatropha kernels that have a potential for use as animal feed (Nithiyanantham et al., 2012; Che Hamzah et al., 2020). Except for lysine, its nutrient profile surpasses the Food and Agriculture Organization of the United Nations (FAO)'s reference protein (Makkar et al., 1998). 
However, it is toxic to humans and animals because of its phorbol esters and other anti- nutrients (trypsin inhibitors, lectins and phytate) and therefore requires detoxification prior to use (Sharath et al., 2014; Rodríguez-González et al., 2018).

Several methods targeting the larger industries and Jatropha farm holdings have been employed and categorised with varying degrees of success to detoxify JKC (Ewane et al., 2017). However, the need for simple cottage techniques for small and large- scale operations persists. Auto-detoxification of JKC has therefore been developed as a pro-poor and prorural detoxification method for JKC (Ewane et al., 2017).

Present study aimed to determine the toxicity of auto-detoxified mixtures JKC and bovine blood (ADMJKC/bb) on brine shrimp (Artemia salina L.). The strategy was to manipulate endogenous and environmental factors that can enhance self-detoxification in mixtures of JKC and bovine blood and identify the most promising treatment combinations. Bovine blood, often used to produce blood meal, highly supports microbial growth, and also represents one of the richest sources of lysine (NRC, 1994). Hence, the (ADMJKC/bb) mix shall enhance the nutrient profile and detoxification rate of JKC. Furthermore, the powdery ground JKC shall easily trap the liquid bovine blood and reduce the need for further processing of blood meal by small-scale farmers (Nithiyanantham and Francis, 2012).

\section{MATERIALS AND METHODS}

\section{Study Location}

The study used the facilities of the Teaching and Research Farm, University of Buea, Cameroon (located at $4.1667^{\circ} \mathrm{N}, 9.2333^{\circ}$ $\mathrm{E}, 578 \mathrm{~m}$ asl). J. curcas seeds were harvested from farms, live fences and plantations in four of Cameroon's five agro-ecological zones (Figure 1): Maroua in the Sudano-Sahel zone, Ngaoundere in the High Guinean Savana, Bamenda in the Western Highlands and Mamfe in the Humid Forest zone with a mono-modal rainfall pattern. Bovine blood was collected from the main abattoir in the town of Buea.

Preparation and pre-treatment of $J$. curcas kernel cake and bovine blood mix

J. curcas seeds were cracked open (using two hard boards) and the extracted kernels de-oiled using a hydraulic press. The J. curcas kernel cake (JKC) obtained was then finely ground using a plate mill and the powder homogenized by hand mixing before further mixing with bovine blood in three different proportions (1/1, 2/1 and 3/1).

Twelve combinations were developed for production and evaluation based on four processing protocols of JKC mixtures with bovine blood $(\mathrm{bb})$ at three mix ratios (Table 1 ). The mixes were

chosen by serially increasing the quantity of JKC in a fixed amount of bovine blood. This gave combination protocols from three ratio mixes and four auto-detoxification treatments. These protocols were inspired by previous studies on the effects of moisture (Abou-

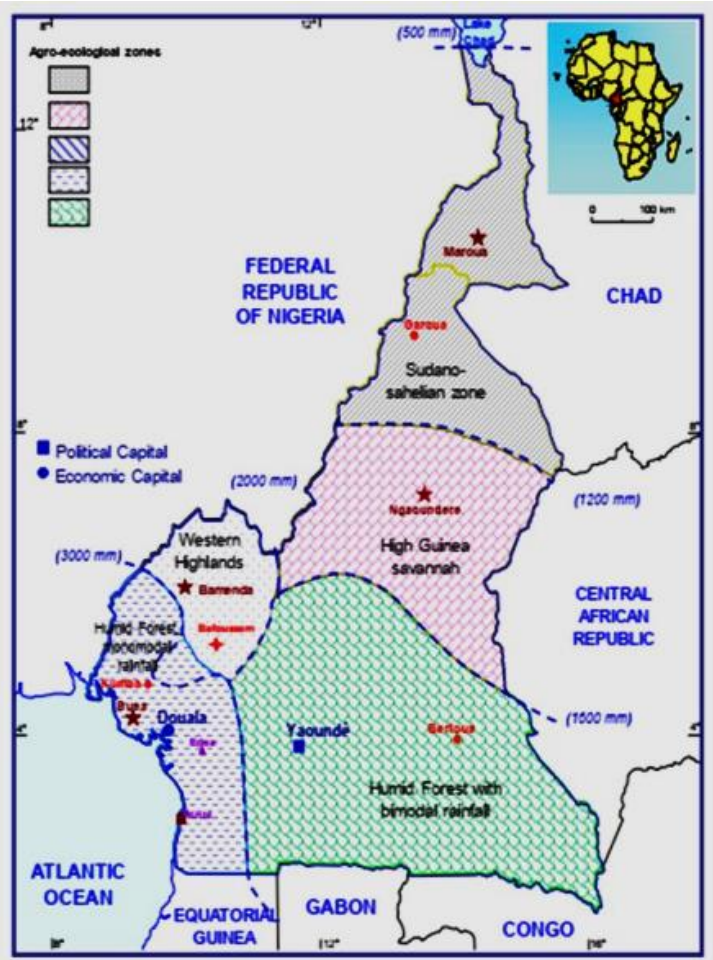

Figure 1 - Location map of Cameroon showing the agro-ecological zones where $J$. curcas seeds were collected.

Arab and Abu-Salem, 2010), spreading (Schmidt and Hecker, 1975) and heat (Aregheore et al., 2003; Martinez-Herrera et al., 2006) on degradation of phobol esters and/or associated anti- nutrients of JKC.

Each combination was replicated 4 times and placed in steel plates arranged on two tables within the performant SJADA (Ewane et al., 2017), operated at full detoxification mode with the air access inlet closed to the minimum level of $50 \mathrm{~cm}^{2}$. Six of the 12 treatment combinations (Protocol code 3 and code 4: X3, Y3, Z3, X4, Y4 and Z4) were remoistened to $66 \%$ dry matter daily, while the other six (Protocol code 1 and code2: X1, Y1, Z1, X2, Y2 and Z2) were not remoistened. About $10 \mathrm{~g}$ of sample were collected weekly from each replicate to evaluate the level of auto-detoxification

Table 1 - Treatment codes of JKC/bb mixing ratios, auto-detoxification and moistening cycles.

\begin{tabular}{|c|c|c|c|c|}
\hline \multirow{2}{*}{$\begin{array}{l}\text { Protocol } \\
\text { Code }\end{array}$} & \multirow{2}{*}{ Auto-detoxification treatment of JKC: bb combination Protocol } & \multicolumn{3}{|c|}{ JKC: bb mixing ratio } \\
\hline & & $X(1: 1)$ & $\mathrm{Y}(2: 1)$ & $\mathrm{Z}(3: 1)$ \\
\hline 1 & Heat, spread and dried - No remoistening & $\mathrm{x} 1$ & Y1 & $\mathrm{Z1}$ \\
\hline 3 & Heat, spread and dried - Remoistened to $66 \%$ dry matter & $\mathrm{X3}$ & Y3 & $\mathrm{Z3}$ \\
\hline 2 & No heat, spread and dried - No remoistening & $\mathrm{X} 2$ & Y2 & $\mathrm{Z2}$ \\
\hline 4 & No heat, spread and dried - Remoistened to $66 \%$ dry matter & $\mathrm{X} 4$ & Y4 & Z4 \\
\hline
\end{tabular}




\section{Preparation of crude methanol auto-detoxified mixtures of JKC/bovine blood extracts (CMJKC/bbE)}

A sample of about $40 \mathrm{~g}$ (10 g per replicate) was collected weekly from each treatment and analysed to determine the progress of auto-detoxification. The replicates of each treatment were pooled and further dried within the apparatus for another week, homogenised and powdered. From the powdered mass, $20 \mathrm{~g}$ were placed in an extraction bottle containing $200 \mathrm{~mL}$ methanol and the methanolic extract obtained by regularly stirring the whole for $72 \mathrm{~h}$ using a rotatory stirrer. The extract was then filtered through Whatman No. 541 filter papers and the crude methanol auto-detoxified mixtures of $\mathrm{JKC} /$ bovine blood extracts $(\mathrm{CMJKC} / \mathrm{bbE})$ obtained by evaporation of the solvent using a rotary evaporator.

\section{Brine shrimp bioassay}

The brine shrimp lethality test (Meyer et al., 1982) was used, with some modifications, to test the toxicity of $\mathrm{CMJKC} / \mathrm{bbE}$. Brine shrimps (Artemia salina Leach) were hatched from eggs in rectangular dishes containing sea water. The dishes were sub-divided by a perforated barrier into two unequal chambers and kept under constant aeration. The bigger chamber receiving the eggs was in the dark while the smaller chamber receiving the hatched napuli in anticipation was under constant light. Forty-eight hours was allowed for the eggs to hatch and the phototropic napuli to mature. At each turn, 10 napuli were drawn using a pipette and placed in a marked vial containing $4 \mathrm{ml}$ of natural seawater. Prior to this, a CMJKC/bbE stock solution of $100,000 \mathrm{ppm}$ was prepared by dissolving $200 \mathrm{mg}$ of CMJKC/bbE in $2 \mathrm{ml}$ of dimethyl sulfoxide (DMSO). The stock solution was then diluted serially with natural seawater to give a series of concentrations for testing $(10000,1000,100,10$ and $1 \mathrm{ppm})$. Three replicates of each concentration were prepared. From each predilution, $1 \mathrm{ml}$ containing $\mathrm{CMJKC} / \mathrm{bbE}$, seawater and DMSO was added to the pre-marked vials containing $4 \mathrm{ml}$ of natural sea water and 10 napuli to make a total volume of $5 \mathrm{ml}$. Negative controls were just dilutions of DMSO in seawater without CMJKC/bbE while un-detoxified whole Jatropha kernel cake served as the positive control.

The vials were incubated under light for $24 \mathrm{~h}$, after which manual counting of dead and immobile napuli at bottom of vial commenced, against a lit background with the aid of a 3X magnifying hand lens. The mortality was calculated as the percentage ratio of the number of dead napuli to the total number of napuli tested after corrections to account for mortalities recorded in the control (Abbott, 1925) as shown in equation 1 . Subsequently corrections were made for $0 \%$ and $100 \%$ as proposed by Ghosh (1984) and presented in equation 2 and equation 3, respectively.

Corrected mortality $(\%)=\left\{\left(M_{\text {obs }}-M_{\text {con }}\right) /\left(100-M_{\text {con }}\right)\right\} \times 100$

Where,

$M_{\text {obs }}$ and $M_{\text {con }}$ were the respective observed and control mortalities.

$0 \%$ Corrected mortality $(\%)=100 \times(0.25 \times n)$

$100 \%$ Corrected mortality $(\%)=100 \times(n-0.25 / n)$

Where,

$\mathrm{n}$ is the number of test animals in each group.
Eqn. 1

\section{Determination of lethal concentration}

The lethal concentration of $\mathrm{CMJKC} / \mathrm{bbE}$ resulting in $50 \%$ mortality of brine shrimp (LC 50 ) was determined from the $24 \mathrm{~h}$ counts by a plot of percentage of the shrimps killed against the logarithm of the $\mathrm{CMJKC} / \mathrm{bbE}$ concentration and the best-fit line was obtained from the curve data by means of regression analysis (MS Excel version 7). The LC $\mathrm{C}_{50}$ was derived from the slope of the best-fit line obtained.

\section{Statistical analysis}

Levene's Test for Equality of Variances was performed on $\mathrm{LC}_{50}$. Also $\mathrm{LC}_{50}$ values were subjected to a one-way analysis of variance (ANOVA) and the significance of the differences between means tested using Duncan's Multiple Range Test (DMRT) (P<0.05). The software used was the IBM SPSS Statistics version 22 (IBM Corp. Released 2013). The most promising $A D M J K C / b b$ treatments were selected after ranking the $\mathrm{LC}_{50}$ from the largest to the smallest values, with the largest values indicating the least toxicity. ANOVA and DMRT were used to detect significant difference of the LC 50 values of $A D M J K C / b b$ treatments

\section{RESULTS}

The evolution of $\mathrm{LC}_{50}$ of crude methanol auto-detoxified mixtures of JKC/bovine blood extracts (CMJKC/bbE) with duration of incubation have been presented in Figure 2, while: comparison of 3 week means of LC 50 of crude methanol autodetoxified mixtures of $\mathrm{JKC} /$ bovine blood extracts $(\mathrm{CMJKC} / \mathrm{bbE})$ is in Table 2. By the third week of the trial, all the 12 treatments had $\mathrm{LC}_{50}$ values above 1000 . This indicates they were all substantially detoxified. There were no significant differences $(\mathrm{P}>0.05)$ among the four Auto-detoxification treatment of JKC: bb combination protocols when compared within rations for each ratio of mixes.

However, there was a general tendency for mean $\mathrm{LC}_{50}$ values to increase across ratios as quantity of JKC increased in the mixture. The only exception was Protocol code3 (the Heat, spread and dried - Remoistened to $66 \%$ dry matter 
protocol). In Protocol code 3, the 2:1 ratio (Y3) is higher than both the 1:1ratio (X3) and 1:3 ratios (Z3). In addition, Protocol code2 (the no heat, spread and dried - no remoistening protocol) recorded a significant difference $(P<0.05)$ between $\mathrm{X} 2$ and $\mathrm{Z} 2$ treatments which are compared across ratios.

The ranking of mean $\mathrm{LC}_{50}$ (Table 3 ) indicates that the most detoxified treatments were Z2=3,047.22, Z4=2, 0130.67 and $Y 3=1,997.64$, while the least detoxified were $X 2=653.65 X 1=736.96$ and $Y 1=1,092.93$. The top two most detoxified treatments ( $Z 2$ and $Z 4)$ differed significantly $(P<0.05)$ from the least two $(X 1$ and $X 2)$.

Of all the treatments evaluated, the extent of lethality was found to be proportional to the concentration of the CMJKCE/bbE. High mortalities were recorded at 1000 ppm and 10,000 ppm, while lower mortalities were recorded at 1 ppm and $10 \mathrm{ppm}$. The graphical representations of the corrected brine shrimp mortalities in week 3 for the most and least detoxified treatments as well as the un treated whole Jatropha kernel cake control are shown in Figure 3.
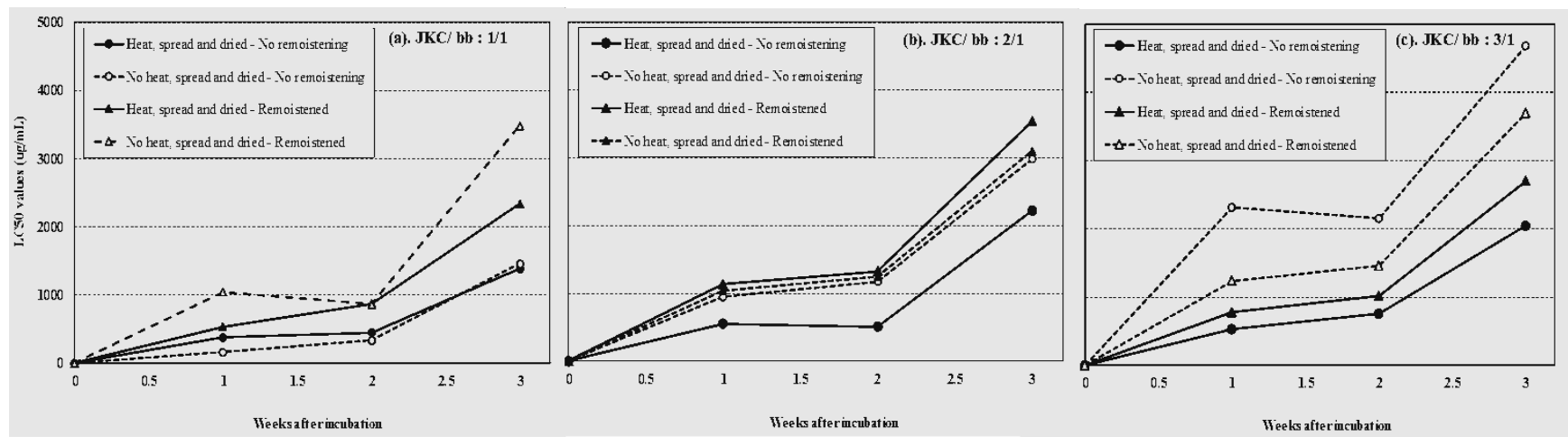

Figure 2 - Evolution of LC 50 of crude methanolic auto-detoxified mixtures of JKC/bovine blood extracts (CMJKC/bbE) with duration of incubation

\begin{tabular}{|c|c|c|c|c|}
\hline \multirow{2}{*}{$\begin{array}{l}\text { Protocol } \\
\text { Code }\end{array}$} & \multirow{2}{*}{$\begin{array}{l}\text { Auto-detoxification treatment of } \\
\text { JKC: bb combination Protocol }\end{array}$} & \multicolumn{3}{|c|}{ JKC: bb mixing ratio } \\
\hline & & $X(1: 1)$ & $Y(2: 1)$ & $Z(3: 1)$ \\
\hline 1 & $\begin{array}{l}\text { Heat, spread an d dried - No } \\
\text { remoistening }\end{array}$ & $\begin{array}{c}X 1 \\
737.0 \pm 844.7\end{array}$ & $\begin{array}{c}\mathrm{Y} 1 \\
1092.93 \pm 783.83 \mathrm{ab}\end{array}$ & $\begin{array}{c}Z 1 \\
1110.46 \pm 652.12 \text { ab }\end{array}$ \\
\hline 2 & $\begin{array}{l}\text { No heat, spread and dried - No } \\
\text { remoistening }\end{array}$ & $\begin{array}{c}X 2 \\
653.7 \pm 604.5 \text { a }\end{array}$ & $\begin{array}{c}\text { Y2 } \\
1700.64 \pm 771.72 \text { ab }\end{array}$ & $\begin{array}{c}Z 2 \\
3047.22 \pm 553.13 b\end{array}$ \\
\hline 3 & $\begin{array}{l}\text { Heat, spread and dried - } \\
\text { Remoistened to } 66 \% \text { dry matter }\end{array}$ & $\begin{array}{c}X 3 \\
1248.5 \pm 815.2 \mathrm{ab}\end{array}$ & $\begin{array}{c}\text { Y3 } \\
1997.64 \pm 643.05 \mathrm{ab}\end{array}$ & $\begin{array}{c}Z 3 \\
1498.18 \pm 406.18 \text { ab }\end{array}$ \\
\hline 4 & $\begin{array}{l}\text { No heat, spread and dried - } \\
\text { Remoistened to } 66 \% \text { dry matter }\end{array}$ & $\begin{array}{c}\mathrm{X} 4 \\
1796.5 \pm 323.7 \mathrm{ab}\end{array}$ & $\begin{array}{c}\text { Y4 } \\
1794.53 \pm 470.58 \text { ab }\end{array}$ & $\begin{array}{c}Z 4 \\
2130.67 \pm 563.01^{b}\end{array}$ \\
\hline
\end{tabular}

\section{Table 3 - Ranking of LC50 of crude methanol auto-detoxified mixtures of JKC/bovine blood extracts (CMJKC/bbE)}

\begin{tabular}{|c|c|c|c|c|c|}
\hline Treatment & Mean ( \pm sem) LC50 & Group & RANK & Best fit equation & $\mathbf{R}^{2}$ \\
\hline $\mathbf{Z 2}$ & $3047.22 \pm 553.13$ & b & 1 & $y=22.568 x-32.795$ & 0.8502 \\
\hline $\mathbf{Z 4}$ & $2130.67 \pm 563.01$ & b & 2 & & \\
\hline Y3 & $1997.64 \pm 643.05$ & ab & 3 & $y=23.337 x-32.795$ & 0.8941 \\
\hline$X 4$ & $1796.54 \pm 323.73$ & ab & 4 & & \\
\hline Y4 & $1794.53 \pm 470.58$ & ab & 5 & & \\
\hline Y2 & $1700.64 \pm 771.72$ & ab & 6 & & \\
\hline $\mathbf{Z 3}$ & $1498.18 \pm 406.18$ & ab & 7 & & \\
\hline X3 & $1248.46 \pm 815.19$ & ab & 8 & & \\
\hline Z1 & $1110.46 \pm 652.12$ & ab & 9 & & \\
\hline Y1 & $1092.93 \pm 783.83$ & ab & 10 & & \\
\hline X1 & $736.96 \pm 844.73$ & a & 11 & $y=21.415 x-21.645$ & 0.8254 \\
\hline X2 & $653.65 \pm 604.48$ & a & 12 & $y=21.799 x-18.954$ & 0.9534 \\
\hline JS Control & 0.05 & & & $y=8.7287 x+61.229$ & 0.6719 \\
\hline
\end{tabular}




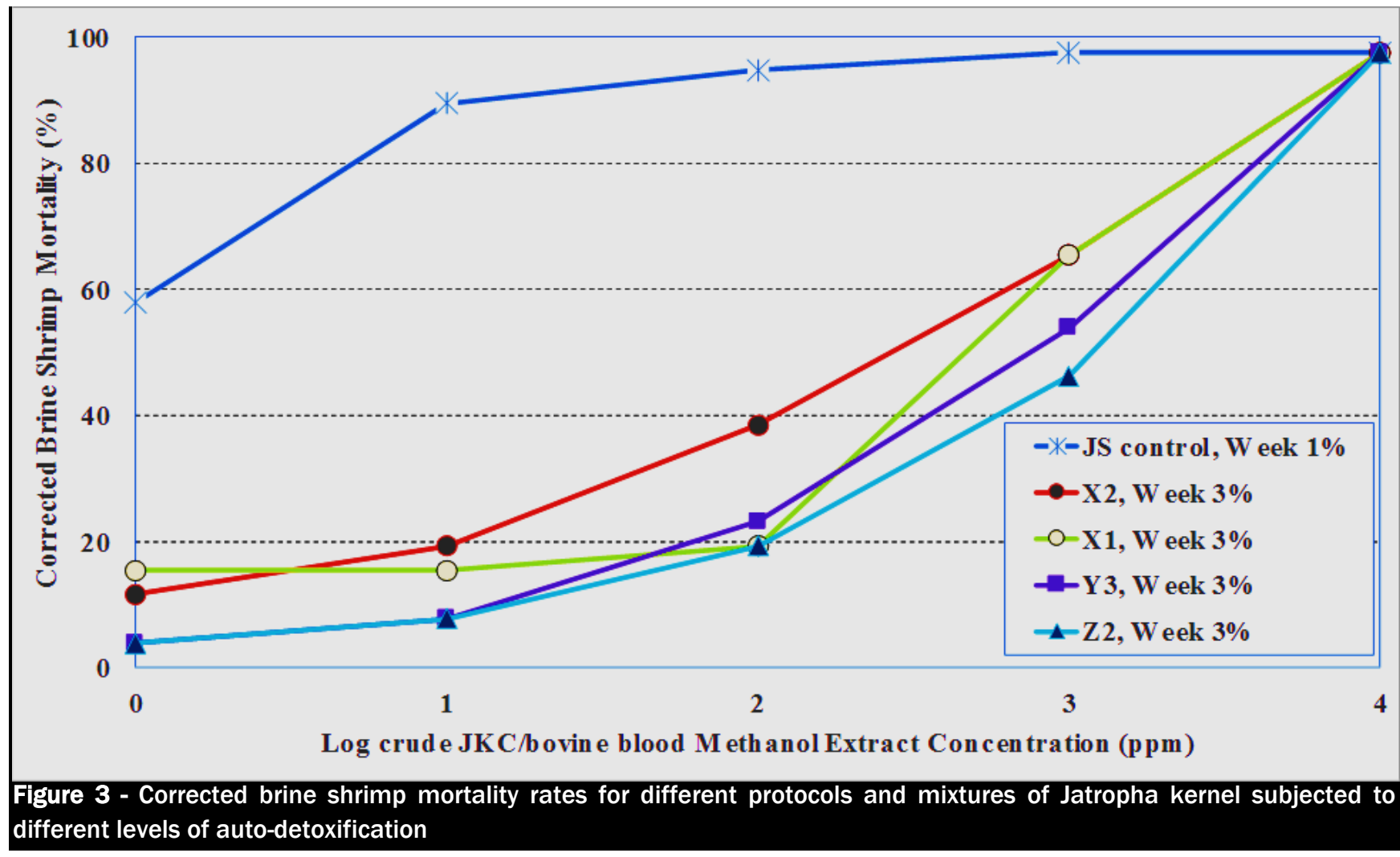

\section{DISCUSSION}

According to Meyer et al. (1982), several extracts derived from natural products which had $\mathrm{LC}_{50} \leq 1000 \mu \mathrm{g} / \mathrm{ml}$ using Brine Shrimp Lethality Test (BSLT) were known to contain physiologically active principles while those with LC $_{50}$ values $>1000$ $\mathrm{ppm}$ were considered inactive. This indicates that all the $12 \mathrm{ADMJKC} / \mathrm{bb}$ ingredients were substantially detoxified after 3 weeks of exposure in the SJADA. The evolution of the $\mathrm{LC}_{50}$ values indicates that detoxification was more rapid with increasing content of JKC in the ADMJKC/bb ingredients. Two ingredients containing a ratio of 3:1 JKC: bb (Z2 and Z4) and two containing JKC: bb ratio of 2:1 (Y3 and Y4) all had LC $_{50}$ values above 1000 within the first week of auto detoxification compared to just one ingredient containing a ratio of 1:1 JKC: bb (X4). Nonetheless, this level of auto-detoxification for even the least ratio mix of JKC with bovine blood is remarkably rapid, when compared to LC $_{50}$ values of auto-detoxified JKC (ADJKC) ingredients produced solo without addition of bovine blood as reported in Ewane et al. (2017). In that study which was performed under similar conditions as the current study, it took 4 weeks for just 3 out of 14 ADJKC test ingredients on trial, to attain LC 50 values above 1000.

Therefore, the addition of bovine blood to JKC probably changed the dynamics of auto- detoxification. According to Thomas (1988), in the live animal blood is generally a sterile medium, possessing innate bacteriostatic and bactericidal abilities. Such antibacterial effects are clearer with gram negative bacteria such as E-coli, and non-virulent strains of Vibro cholerae, Haemophilus influenae, salmonellae and shigellae. Out of the animal, however, bovine blood is a rich nutrient medium encouraging the growth of several microbes. Adding bovine blood to JKC may therefore increase the range of microbes in the mixture which would rapidly increase the level of auto-detoxification. Kasuya et al. (2013) increased the level of bio- detoxification of JSC by adding $10 \%$ eucalyptus bark. From the data obtained, they deduced that the importance of adding eucalyptus bark served to balance carbon and nitrogen and decrease the fat content, thus resulting in improved fungal growth. They concluded that their results support the hypothesis that phorbol ester degradation occurs because of co-metabolism by the enzymes responsible for lignin de-polymerization.

Even though the differences were not significant $(P>0.05), A D M J K C / b b$ produced by subsequent remoistening irrespective of whether they were preheated or not (Protocol code 3 and code 4: Z3, Y3, X3, Z4, Y4, X4) as a group were among the top most detoxified, while the ADMJKC/bb preheated without subsequent remoistening (Protocol code 1: X1, Y1 and Z1) were the least detoxified. Interestingly, the actual most detoxified, median most detoxified and actual least detoxified $A D M J K C / b b$ ingredients were respectively $Z 2$, Y2 and $X 2$, from protocol code 2. These ingredients were unheated and un-remoistened; the difference between the three ingredients was the ratio of mixing JKC with bovine blood. They were respectively mixed at 3:1, 2:1 and 1:1 for Z2, Y2 and X2. The protocol code 1 (Z1, Y1, and X1) $A D M J K C / b b$ ingredients which were the least detoxified as a group followed a similar detoxification ranking with $Z 1$ as the most detoxified and $X 1$ as the least detoxified for that group. What was common among the Protocol code 1 and code 2: Z1, Y1, X1 Z2, Y2, X2 groups was that they were all undergoing a form of unperturbed solid state auto-detoxification compared to their daily remoistened counterparts of Protocol code 3 and code 4 (Z3, Y3, X3 \& Z4, Y4, X4). The only 
difference is that while the Protocol Code 1 (Z1, Y1, X1) group was heated, the Protocol code 2 (Z2, Y2, X2) group was unheated. Similarly, while the Protocol code $3(Z 3, Y 3, X 3)$ group was preheated, the protocol code 4 (Z4, Y4, X4) group was unheated.

The differences observed among the various ratio mixes of JKC with blood therefore, probably indicate that the higher the ratio of JKC in the mixture, the higher the level of innate auto-detoxifying microbial inoculum. The hypothesis that needs to be verified is that "Microbes supporting auto-detoxification are present on the JKC and either act or wait for their opportunity to act in an ecological succession. Bovine blood provides a trigger (probably nutrients in simple molecules plus additional microbes) which boosts the rapid growth, development and succession of these microbes". Evidence from an earlier study by Ewane et al. (2017) in support of this hypothesis is that powdered JKC treatments with neither addition of water nor lye (un-moistened solar spread-USS- and un-moistened diffuse daylight spread-UDC-) treatments were substantially detoxified, having $\mathrm{LC}_{50}$ of 63.89 and 5.22 respectively after four weeks of exposure in the Solar J. curcas Auto-detoxification Apparatus (SJADA) and Diffuse Daylight J. curcas Auto-detoxification Apparatus (DJADA) respectively. The observation that the ADMJKC/bb preheated without subsequent remoistening (Protocol code 1: $\mathrm{X} 1, \mathrm{Y} 1$ and Z1) as a group were the least detoxified is a pointer that the initial inoculum was probably destroyed by heat and a succession was slower to take off in the absence of added moisture. The abnormal higher ranking of Y3 over Z3 in Protcol code 3 is possibly an indication that release of nutrients and other factors from bovine blood as a proportion to available microbial inoculum to auto-detoxifying microbes in heat treated and subsequently remoistened ADMJKC/bb could also be a determinant to the rate of auto- detoxification.

Furthermore, the results of Chikpah and Demuyakor (2012), who observed that approximately $60 \%$ reduction in crude phorbol ester levels can be achieved within 21 days of spontaneous fermentation of $J$. curcas kernel meal, supports the hypothesis that JKC contains some innate auto-detoxifying microbial inoculum. As defined in Ewane et al. (2017), auto-detoxification is a self-detoxification process induced by endogenous and environmental factors including enzymes, microbes, sunlight, temperature, humidity and wind. It is the natural way to transform the toxic J. curcas seeds into an innocuous material. These processes take considerable time under natural conditions but their duration can be shortened by human manipulation. The results of this present study therefore highlight the possible role of microbes in the autodetoxification process. Working with pure microbial cultures, some authors including Belewu and Akande (2010), Belewu et al. (2010), Bose and Keharia (2013), Kasuya et al. (2013) and Azhar et al. (2014) have confirmed the role of fungi in the detoxification of JKC, while others including El-Zelaky et al. (2011), Phengnuam and Suntornsuk (2013), Widiyastuti et al. (2013) and Chang et al. (2014) have confirmed the role of bacteria in the detoxification of JKC.

All the $12 \mathrm{ADMJKC} / \mathrm{bb}$ ingredients were substantially detoxified; however, the top three most detoxified ingredients (Z2, Z4 and Y3) have been selected for further development. Any of the bottom nine (X4, Y4,Y2, Z3,X3,Z1,Y1,X1, and X2) may still be tested with animal models for further differentiation.

\section{CONCLUSION}

The addition of bovine blood to Jatropha Kernel Cake (JKC) changed the dynamics of auto-detoxification. Microbes supporting auto- detoxification are present on the JKC and either act or wait for their opportunity to act in an ecological succession. Bovine blood provides a trigger (probably nutrients in simple molecules plus additional microbes) which boosts the rapid growth development and succession of these microbes. Also, blood, which is the richest natural source of lysine, could supplement the reported lysine deficiency in JKC and the combined auto-detoxified mixtures Jatropha kernel cake and bovine blood; (ADMJKC/bb), would potentially become a better feed ingredient than either blood meal alone or JKC alone. Consequently, the top three most detoxified ingredients (Z2, Z4 and Y3) have been selected for further development and testing as feed ingredient for farm animals. However any of the bottom nine (X4, Y4,Y2, $\mathrm{Z3}, \mathrm{X} 3, \mathrm{Z1}, \mathrm{Y} 1, \mathrm{X} 1$, and $\mathrm{X} 2$ ) may still be tested with animal models for further differentiation.

\section{DECLARARATIONS}

\section{Corresponding author's Email: ewane.divine@ubuea.cm ; (1) ОRсі: 0000-0002-7807-4056-}

\section{Authors' contribution:}

D.Ewane conceived the study, designed the study, collected data, contributed in data analysis, and writing the manuscript, coordinated the inputs of all the other authors; B.O.Oben and K.J.N.Ndamukong performed critical reviewing of the manuscript and supervision of the study; K.A.Etchu performed critical reviewing of the manuscript; E.E.Ehabe contributed in design of study, data analysis and writing the manuscript; J.M.Chah contributed in data collection and write up of the manuscript; K.F.Chah contributed in conception of the study, design of study, data analysis and critical reviewing of the manuscript; P.M.Oben performed critical reviewing of manuscript and coordinated the study.

\section{Competing interest}

The authors have not declared any conflict of interest

\section{Acknowledgements}

Thanks to the University of Buea for financial support to purchase the Jatropha seeds. 


\section{REFERENCES}

Abou-Arab A and Abu-Salem FM (2010). Nutritional quality of Jatropha curcas seeds and effect of some physical and chemical treatments on their anti-nutritional factors. African Journal of Food Science, 4(3): 93-103. https://doi.org/10.5897/AJFS.9000205 I Google Scholar

Aregheore EM, Becker K and Makkar HPS (2003). Detoxification of a toxic variety of Jatropha curcas using heat and chemical treatments, and preliminary nutritional evaluation with rats. South Pacific Journal of Natural Science, 21(1): 50-56. http://repository.usp.ac.fj/id/eprint/2745 I Google Scholar

Azhar N, Norhani A, Wan Z, Syahida A, Ehsan O, Faridah A and Youssuf G (2014). Detoxification of toxic phorbol esters from malaysian Jatropha curcas Linn. kernel by Trichoderma spp., and Endophytic Fungi. International Journal of Molecular Sciences, 15(2): 22742288. https://dx.doi.org/10.3390\%2Fijms15022274 I Google Scholar

Belewu MA and Akande BA (2010). Biological upgrading of the nutritional quality of Jatropha curcas kernel cake: effect on performance characteristics of goat. International Research Journal of Biotechnology, 1(2): 19-22. http://www.interesjournals.org/IRJOB I Google Scholar

Belewu MA and Sam R (2010). Solid state fermentation of Jatropha curcas kernel cake: proximate composition and anti- nutritional components. Journal of Yeast and Fungi Research, 1 (3): 44-46. https://doi.org/10.5897/JYFR.9000046 I Google Scholar

Belewu MA, Belewu KY and Ogunsola FO (2010). Nutritive value of dietary fungi treated Jatropha curcas kernel cake: voluntary intake, growth and digestibility coefficient of goat. Agriculture and Biology Journal of North America, 1 (2): 135 - 138. https://citeseerx.ist.psu.edu/viewdoc/download?doi=10.1.1.212.9286\&rep=rep1\&type=pdf I Google Scholar

Bose A and Keharia H (2013). Phorbol ester degradation in Jatropha seedcake using white rot fungi. 3 Biotech, 4(4): 447-450. https://doi.org/10.1007/s13205-013-0174-9 I Google Scholar

Chang CF, Weng JH, Lin KY, Liu LY and Yang SS (2014). Phorbol esters degradation and enzyme production by Bacillus using Jatropha seed cake as substrate. International Journal of Environmental Pollution and Remediation, 2(1):30-36. https://ijepr.avestia.com/2014/005.html I Google Scholar

Che Hamzah NH, Khairuddin N, Siddique BM, and Hassan MA (2020). Potential of Jatropha curcas L. as biodiesel feedstock in Malaysia: a concise review. Processes, 8: 786. https://doi.org/10.3390/pr8070786 I Google Scholar

Chikpah SK and Demuyakor B (2012). Effects of spontaneous solid-state fermentation on the proximate and antinutrients composition of Jatropha curcas kernel meals obtained from four different agro-climatic areas of Ghana: detoxification approach. International Journal of Scientific and Technology Research, 1(11): 112-117 https://www.ijstr.org/paper-references.php?ref=|JSTR-1212-5603 I Google Scholar

El-Zelaky OA, Khalifa EI, Mohamed AH, Bahera KM and Hussein AM (2011). Productive and reproductive performance of Rahmani male lambs fed rations containing Jatropha cake. Egyptian Journal of Sheep \& Goat Sciences, 6 (2): $15-24$. https://ejsgs.journals.ekb.eg/article_27026_1517df0f650691d766ca06ef28525321.pdf I Google Scholar

Ewane D, Oben PM, Ndamukong KJN, Oben BO, Etchu KA and Chah KF (2017). Evaluating auto-detoxification of Jatropha curcas Linnaeus, 1753 kernel cake with brine shrimp Artemia salina (Linnaeus, 1758) lethality test. African Journal of Biotechnology, 16 (31): 16601669. https://doi.org/10.5897/AJB2017.15889 I Google Scholar

Ghosh MN (1984). Fundamentals of Experimental Pharmacology. Scientific Book Agency, Second Edition, Calcutta. P 25. https://www.worldcat.org/title/fundamentals-of-experimental-pharmacology/oclc/759909460 I Google Scholar

IBM Corp. Released (2013). IBM SPSS Statistics for Windows, Version 23.0. Armonk, NY: IBM Corp. Google Scholar

Kasuya MCM, Rodrigues da Luz JM, Pereira LP da S, Soares da Silva J, Montavani HC and Rodrigues MT (2013). Bio-detoxification of jatropha seed cake and its use in animal feed. Intech Open, Croatia. Available from: https://www.intechopen.com/books/biodieselfeedstocks-production-and-applications/bio-detoxification-of-jatropha-seed-cake-and-its-use-as-animal-feed I Google Scholar

Maghuly F and Laimer M (2013). Jatropha curcas, a biofuel crop: functional genomics for understanding metabolic pathways and genetic improvement. Biotechnology Journal, 8(10): 1172-1182. https://doi.org/10.1002/biot.201300231 I Google Scholar

Makkar HPS, Aderibigbe AO and Becker K (1998). Comparative evaluation of non-toxic and toxic varieties of Jatropha curcas for chemical composition, digestibility, protein degradability and toxic factors. Food Chemistry, 62 (2): 207-215. https://doi.org/10.1016/S03088146(97)00183-0 I Google Scholar

Martinez-Herera J, Siddhuraju P, Francis G, Davila-Ortiz G and Becker K (2006). Chemical composition, toxic/antimetabolic constituents, and effects of different treatments on their levels, in four provenances of Jatropha curcas, from Mexico. Food Chemistry, 96(1): 8089. https://doi.org/10.1016/j.foodchem.2005.01.059 I Google Scholar

Meyer BN, Ferrigni NR, Putnam JE, Jacobsen LB and McLaughlin JL (1982). Brine Shrimp: a convenient general bioassay for active plant constituents. Planta Medica, 54(5): 31-34. https://www.thieme-connect.com/products/ejournals/abstract/10.1055/s-2007$\underline{971236}$ I Google Scholar

Nithiyanantham S, Siddhuraju P, and Francis G (2012). Potential of Jatropha curcas as a biofuel, animal feed and health products. Journal of the American Oil Chemists' Society, 89: 961-972 https://doi.org/10.1007/s11746-012-2012-3 I Google Scholar

NRC (1994). Nutrient requirements for Poultry. $9^{\text {th }}$ Ed. National Academy Press Washington DC. USA https://doi.org/10.17226/2114

Phengnuam T and Suntornsuk W (2013). Detoxification and anti-nutrients reduction of Jatropha curcas seed cake by Bacillus fermentation. Journal of Bioscience and Bioengineering, 115(2): 168-172. https://doi.org/10.1016/j.jbiosc.2012.08.017 I Google Scholar

Rodríguez-González H, López-Aguilar MR, Fonseca-Madrigal J, Martínez-Palacios CA, and García-Ulloa M (2018). Use of a mixture of vegetal (Jatropha curcas) and animal (fish silage) byproducts as protein source in shrimp (Litopenaeus vannamei) diets. Revista Brasileira de Zootecnia, 47: e20170165. https://doi.org/10.1590/rbz4720170165 I Google Scholar

Sharath BS, Mohankumar BV, and Somashekar D (2014). Bio-detoxification of phorbol esters and other anti-nutrients of Jatropha curcas seed cake by fungal cultures using solid-state fermentation. Applied Biochemistry and Biotechnology, 172(5): 2747-2757. https://doi.org/10.1007/s12010-013-0698-9 I Google Scholar

Thomas CGA (1988). Medical microbiology. $6^{\text {th }}$ ed. University press Cambridge, ISBN $13: 9780702004551$. https://www.cambridge.org/ir/academic/subjects/life-sciences/microbiology-and-immunology/general-microbiology-7thedition?format=PB\&isbn=9780521439800

Widiyastuti T, Prayitno $\mathrm{CH}$ and Iriyanti N (2013). Digestibility and blood metabolite profiles of chicken fed fermented Jatropha seed meal. Animal Production, 15(2): 98-105. https://media.neliti.com/media/publications/66870-EN-digestibility-and-blood-metaboliteprofi.pdf I Google Scholar 